\title{
Management of isolated high grade blunt pancreatic injury; case report on lesser aggressive approach
}

\author{
Manjit Singh*, Mritunjay Sarawagi, Anjay Kumar, Uday Kumar
}

Department of Surgery, Rajendra Institute of Medical Sciences, Ranchi, Jharkhand, India

Received: 27 November 2018

Revised: 02 January 2019

Accepted: 01 April 2019

\section{*Correspondence:}

Dr. Manjit Singh,

E-mail: manjit05.singh@gmail.com

Copyright: (C) the author(s), publisher and licensee Medip Academy. This is an open-access article distributed under the terms of the Creative Commons Attribution Non-Commercial License, which permits unrestricted non-commercial use, distribution, and reproduction in any medium, provided the original work is properly cited.

\begin{abstract}
Isolated high grade pancreatic injury is rare after blunt abdominal trauma. It is a rare entity to appreciate intraoperatively and a high index of suspicion should always be kept in mind to reach the diagnosis. We are presenting our experience of four cases with moderate to high grade isolated pancreatic injury which were managed in a lesser aggressive approach and had an uneventful outcome.
\end{abstract}

Keywords: Distal transection, Grade III pancreatic injury, Pancreatic trauma

\section{INTRODUCTION}

Tavers in 1827 was the first to report a patient with blunt pancreatic injury (the Lancet). ${ }^{1}$ Pancreatic duodenum complex injury accounts a very small percentage (6-7\%) in blunt abdominal trauma. Isolated pancreatic injuries are even rarer. ${ }^{2}$

The diagnosis of pancreatic injury poses a great challenge and requires multimodality diagnostic aids besides high index of clinical suspicion. The management of such cases is based mainly on the hemodynamic condition of the patient. With the subjugation of CT of the abdomen and the evolving techniques like ERCP the so called trauma Whipple has been moved by "damagecontrol surgery."'The grading and management of pancreatic injuries have been laid by American Association for the Surgery of Trauma (AAST), however their clinical usefulness is limited. ${ }^{3,4}$

Aim of the study was to present our experience with four cases of isolated blunt pancreatic trauma and to discuss the contemporary literature in this context.

\section{CASE REPORT}

We are discussing here four cases of isolated blunt pancreatic injury which we came across during emergency. As evident the mode of injury in all the cases was road traffic accident, all patients at the presentation were referred from some centers and were hemodynamically stable (Table 1). All the patients were young having pancreatic injuries ranging from grade II to grade IV on cross sectional imaging (CECT abdomen in our series). Serum amylase was raised in all but one patient. All the patients after a brief phase of workup underwent exploratory laparotomy.

On laparotomy each case had a distinct pancreatic parenchymal injury without main pancreatic duct (MPD) disruption.

Case 4 had complete transection at body. The patients were managed with thorough peritoneal lavage (warm isotonic saline; 2-2.5 liters) while the transection was primarily repaired. All the patients were put on closed suction drain (Table 2). 
All the patients were observed thoroughly for outcomes. Initial post-operative phases were uneventful. Case 1 developed POPF which was conservatively managed while the rest of the cases had pseudocyst which were internally drained. No other complications were noted and patients are on regular follow up without any significant discomfort (Table 3).

Table 1: Initial presentation and workup of patients.

\begin{tabular}{|lllllll|}
$\begin{array}{l}\text { S. } \\
\text { No. }\end{array}$ & $\begin{array}{l}\text { Age } \\
\text { (yrs) }\end{array}$ & Sex & $\begin{array}{l}\text { Mode of } \\
\text { injury }\end{array}$ & $\begin{array}{l}\text { Hemodynamic } \\
\text { condition }\end{array}$ & $\begin{array}{l}\text { Serum } \\
\text { Amylase }\end{array}$ & CT Abdomen (Grade) \\
\hline 1 & 28 & M & RTA* & Stable & High & Pancreatic Laceration (II) \\
\hline 2 & 27 & F & RTA & Stable & Normal & Distal Transection (III) \\
\hline 3 & 21 & M & RTA & Stable & High & Distal Transection (III) \\
\hline 4 & 17 & M & RTA & Stable & High & $\begin{array}{l}\text { Hemoperitoneum with complete } \\
\text { transection at body (IV) }\end{array}$ \\
\hline
\end{tabular}

* Road Traffic Accident

Table 2: Intra-operative findings and procedure done for each patient.

\begin{tabular}{|ll|}
\hline Intra-operative finding(s) & Procedure done \\
\hline Pancreatic Laceration & EL* with peritoneal lavage+ drain**. \\
\hline Distal Pancreatic Transection & EL with peritoneal lavage+ drain. \\
\hline Distal Pancreatic Transection & EL with peritoneal lavage+ drain. \\
\hline Complete Transection at Body & EL with primary repair+ drain. \\
\hline
\end{tabular}

* Exploratory Laparotomy, ** Intra-abdominal closed suction drain.

Table 3: Follow up and management of complications.

\begin{tabular}{|lll|}
\hline Diagnosis & Complication(s) & Management \\
\hline Pancreatic Laceration & POPF* & Conservative \\
\hline Distal Pancreatic Transection & Pancreatic Pseudocyst & Drainage** \\
\hline Distal Pancreatic Transection & Pancreatic Pseudocyst & Drainage** \\
\hline Complete Transection at Body & Pancreatic Pseudocyst & Drainage** \\
\hline
\end{tabular}

* Post-operative Pancreatic Fistula, ** Cystogastrostomy

\section{DISCUSSION}

Pancreatic duodenal complex injury carries 20\% mortality rate. Non-operative management (NOM) and damage control surgery has become the buzzwords in the management of hemodynamically stable and unstable patient's respectively. ${ }^{3-6}$

Isolated pancreatic injury poses a diagnostic and therapeutic challenge. Hemodynamically stable patients with injuries to the pancreas and/or duodenum may exhibit only subtle signs because of the retroperitoneal location of these organs. Patients with a history of acceleration / deceleration injury; forceful anterior compression of the abdomen, such as from kicks or handlebar injuries and lower thoracic and upper lumbar vertebra fractures are at increased risk.

A "seat belt sign" across the upper and middle abdomen should suggest the possibility of serious intra-abdominal injury. However, the physical examination can be remarkably benign; abdominal pain and peritoneal signs sometimes take days to develop. For all these reasons, a high index of suspicion is essential to avoid missing an injury. ${ }^{7,8}$

It can be appreciated that serum amylase may remain normal in upto $35 \%$ of patients with a pancreatic transection. ${ }^{9}$ In our experience, three patients had raised serum amylase level while it was normal in a patient having distal pancreatic transection. We can infer that serum amylase at presentation is not a reliable indicator of pancreatic injury (Table 1).

The available guidelines swing from non-operative management to sometimes trauma Whipple (TW). Grade I and II injuries can be treated with no more than surgical hemostasis and drainage. Liberal use of drains is on the rise as many minor appearing injuries will drain for several days.

Grade III injuries with duct disruption are managed surgically. In this context emergency ERCP with duct stenting is on the rise. Grade IV and V are usually associated multiple injuries and management includes resection, pyloric exclusion and in extreme situation TW. ${ }^{10}$ 
Our experience is reflecting our basic learning of lesser aggressive surgery in emergency, has given us satisfactory results. All the cases sustained isolated pancreatic injury after road traffic accident and underwent exploratory laparotomy and were treated with minimum required intervention(s).

The first case had pancreatic laceration and was managed through lavage and closed suction drain. He further developed POPF which was conservatively managed. The second and third cases had grade III pancreatic injury which were managed by lavage followed by drain developed pancreatic pseudocyst which was drained internally (cysogastrostomy). The last case had grade IV injury and underwent primary repair and elective internal drainage subsequently after developing pancreatic pseudocyst (Table 2, 3).

All the four cases were followed eventually and had a stable phase post-surgery for complication(s). D Anna Reddy et al. concluded in their case report that grade 3 and grade4 injuries can be initially managed nonsurgically with minimal morbidity and mortality, and late sequelae can be managed electively avoiding major surgeries in emergency setting. ${ }^{11}$

\section{CONCLUSION}

Isolated Grade 3 and 4 pancreatic injuries require high index of clinical suspicion for diagnosis and management. Our experience has been managing such cases with an approach which a step down from the published steps in literatures and managing the complications electively.

Funding: No funding sources Conflict of interest: None declared Ethical approval: Not required

\section{REFERENCES}

1. Tavers B. Rupture of the pancreas, Lancet. 1827; $12: 384$.

2. Shilyansky J, Sena LM, Kreller M, Chait P, Babyn PS, Filler RM, et al. Nonoperative management of pancreatic injuries in children. $J$ Pediatr Surg. 1998;33:343-9.

3. Moore EE. Organ injury scaling. II. Pancreas, duodenum, small bowel, colon, and rectum, J Trauma. 1990;30:1427-9.

4. Hirshberg A, Mattox KL. Top knife: the art and craft of trauma surgery, New York, 2006, SpringerVerlag, p 127.

5. Hoey BA, Schwab CW. Damage control surgery, Scand J Surg. 2002;91:92-103.

6. Phelan HA, Velmahos GC, Jurkovich GJ, Friese RS, Minei JP, Menaker JA, et al. An evaluation of multidetector computed tomography in detecting pancreatic injury: results of a multicenter AAST study. J Trauma. 2009;66:641-7.

7. Bansal V. The utility of seatbelt signs to predict intra-abdominal injury following motor vehicle crashes, Traffic Ing Prev. 2009;10:567-72.

8. Wright MJ, Stanski C. Blunt pancreatic trauma: a difficult injury, South Med J. 2000;93:383-5.

9. Adamson WT. Serum amylase and lipase alone are not cost effective screening methods for pediatric pancreatic trauma, J Pediatr Surg. 2003;38:354-7.

10. Biffl WL. Duodenum and pancreas. In: Mattox KL, Moore EE, Feliciano DV, eds. Trauma. 7th ed. New York, NY: McGraw-Hill. 2012:603-19.

11. Reddy DA, Reddy VV, Sivaramakrishna G, Chandramaliteeswaran C, Rao MB. Pancreatic trauma: a less aggressive approach is safe. HPB. 2016;18:e451.

Cite this article as: Singh M, Sarawagi M, Kumar A, Kumar U. Management of isolated high grade blunt pancreatic injury; case report on lesser aggressive approach. Int Surg J 2019;6:1789-91. 